\title{
Formação humana e sociedades plurais
}

Pedro Goergen*

\section{RESUMO}

O presente ensaio trata da formação humana em sociedades plurais, partindo de uma breve recuperação histórica da problemática para, a seguir, deter-se no cenário contemporâneo desde uma perspectiva epistêmica mais ampla, no intuito de mostrar que o tema da pluralidade/complexidade não se restringe ao campo das humanidades. Trata-se muito mais de uma crise geral das certezas da racionalidade moderna. Finalmente, tenta-se mostrar que o tema da pluralidade desafia a tradição pedagógica, cujas práticas fundavam-se, precisamente, nos conceitos de certeza e autoridade, que precisam ser repensados desde a perspectiva da pluralidade, do reconhecimento e da dialogicidade.

Palavras-chave: Formação. Sociedades plurais. Alteridade. Reconhecimento. Dialogicidade.

O tema enunciado no título envolve dois assuntos de grande complexidade: formação humana e sociedades plurais. Tomados isoladamente, já são temas amplos e polêmicos; relacionados entre si, sua complexidade aumenta e aprofunda-se. O conceito de sociedade plural anda de passo com outros conceitos, tais como os de globalização, multiculturalismo e cosmopolítica, ora em grande evidência, mas já presentes na nossa história pregressa. São temas amplos inerentes à cultura humana como um todo, desde sua origem até nossos dias. Esse caráter histórico e universal é bastante visível no caso da formação, até mesmo porque se trata do processo constituinte do humano. Quando, porém, falamos de sociedade plural ou multicultural, parece se tratar de um assunto muito recente, antes desconhecido.

Para iniciar, tentarei mostrar, com breves referências históricas, que a sociedade plural não é uma realidade tão recente quanto muitas vezes se imagina. Novas mesmo são suas características contemporâneas, sobretudo sua radicalidade e incidência na vida subjetiva, social e institucional. Olhando para o passa-

Recebido: 12/09/2013 - Aprovado: 15/12/2013

http://dx.doi.org/10.5335/rep.v21i1.3870

Professor titular da Universidade de Sorocaba (Uniso) e titular (colaborador) da Universidade Estadual de Campinas (Unicamp). Possui doutorado em Filosofia pela Ludwig Maximilians Universität München (1975) e pós-doutorado na Universidade de Bochum e no Instituto Max Planck da Alemanha. E-mail: pedro.goergen@hotmail.com. 
do, devemos admitir que já houve cenários plurais em que sociedades distintas quanto a estrutura social, visões de mundo e expectativas éticas encontravam-se e confrontavam-se. No mundo grego, no Império Romano, no Renascimento e na Modernidade ocorreram confluências e, não raro, choques entre culturas com diferentes tradições, valores e estruturas sociais.

As viagens e relações políticas de Platão, o trabalho de Aristóteles como preceptor do macedônio Alexandre, as origens, viagens e os ensinamentos dos sofistas e, na própria Grécia, as culturas de cidades autônomas e culturalmente tão distintas quanto Atenas e Esparta; a grande confluência das culturas grega, romana e judaica no cristianismo; a extensão do Império Romano e sua política de preservação e incorporação das culturas conquistadas; os burgos medievais, centros de intercâmbios de produtos e culturas; a biblioteca de Alexandria, um verdadeiro centro pluricultural; as culturas árabes na católica Península Ibérica; a chegada dos chamados povos bárbaros do norte; os grandes centros universitários de mestres e estudantes vindos de diferentes países e culturas são apenas alguns exemplos de pluriculturalismo na história da civilização ocidental. Não se trata de negar o caráter inovador da globalização e do multiculturalismo mais recentes, mas, simplesmente, de reconhecer os antecedentes cujos elos conduzem e desvendam o movimento civilizatório, oculto ao olhar linear.

Paralelamente a esse movimento plural de encontros e confluências, podemos perceber, também, a permanente busca de transcendência, homogeneidade, universalidade e domínio. Na época dos poetas, impõe-se o modelo de virtude das divindades mitológicas; no tempo dos filósofos, o das essências metafísicas; no período dos teólogos, o da divindade cristã e, finalmente, nos séculos do iluminismo, o modelo da racionalidade científica moderna. Homero descreveu os feitos virtuosos de seus heróis com clara intenção educativa para todos os gregos; Sócrates perturbou seus interlocutores defendendo a verdade interior como orientação segura frente às opiniões mutantes e passageiras; Platão alinhou a educação ao paradigma absoluto do ideal, alicerçado no conceito fundamental de verdade, alcançável pela racionalidade dialética; os Sofistas, críticos da aristocracia sanguínea e epistêmica, correram por fora, colocando o homem como medida de todas as coisas; Aristóteles, crítico do idealismo platônico, propôs a abstração e a lógica como acesso à verdade.

Também no medievo, predominou o enfoque transcendental, agora de corte religioso/cristão, concentrando-se, de uma parte, sobre a fé interior e, de outra, sobre a observação dos mandamentos de Deus e da Igreja. Os ignorantes dessas verdades, os rudes, como dizia Santo Agostinho, deveriam ser instruídos na verdade única revelada por Deus ou prescrita pela Igreja. Nem mesmo as heresias ao tempo de Agostinho, as polêmicas fideísta/racionalistas ao tempo de Tomás e o grande cis- 
ma ao tempo de Lutero puseram em questão a verdade religiosa como fundamento da salvação e, portanto, como referência consensual de todo o processo formativo.

A grande mudança, antes anunciada no debate entre dominicanos e franciscanos na Universidade de Paris, chegou com o humanismo pré-moderno. Os novos ventos seculares tremulavam a bandeira da razão enquanto fonte segura e universal de conhecimento dos segredos naturais, sociais e humanos. A suposição de uma ordem inerente à natureza e o uso de um novo método racional de averiguação das leis subjacentes abriam a perspectiva de maior permeabilidade entre fé e razão. Não a revelação, mas a experiência deveria aportar, de então em diante, os insumos necessários a uma nova ordem epistêmica, finalmente livre do obscurantismo metafísico e teológico.

O gênio inaugural de cientistas como Copérnico (1473-1543), Bacon (15611626), Galileo (1564-1642), Kepler (1571-1630), Newton (1642-1727) e tantos outros menos estelares lançou os fundamentos de um novo modelo de conhecimento fundado exclusivamente na capacidade racional do sujeito moderno, pretensamente livre de quaisquer recursos externos não referenciados à experiência e ao raciocínio. Fundada na experiência auscultada com rigor e claridade, a razão se encarregaria de fornecer segurança e rumo ao procedimento humano. Abbagnano e Visalberghi assim resumem a fundamentação filosófica dessa notável transformação: Descartes tenta encontrar "na existência do sujeito pensante, cujo ser é evidente a si mesmo, o princípio que garanta a validade do conhecimento humano e a eficácia da ação humana sobre o mundo" (1990, p. 293). A partir desse momento, o homem vê-se como um microcosmo espelhado no funcionamento do macrocosmo da natureza e do universo, capaz de organizar com rigor e proveito sua própria vida. Comenius (1592-1671) e, desde outra perspectiva, também Rousseau (1712-1778) formularam seus projetos pedagógicos sobre o pano de fundo dessa relação.

Hobbes (1588-1679) amplia a imagem cartesiana do mecanismo natural, aplicando-a à sociedade civil. Para o filósofo inglês, também a existência humana como um todo é uma ordem necessária, regida por princípios e postulados acessíveis à experiência do ser humano em sociedade, à semelhança dos princípios e leis naturais detectados pela ciência física. Na formulação posterior de Spinoza (16321677), Deus sive natura, ou seja, a natureza, inclusive a humana, é determinada pela natureza necessária de Deus. Na sua expressão mais extremada, o filósofo entende que Deus é a própria ordem geométrica do universo, de modo que a forma exterior da ética é precisamente a mesma dos tratados de geometria. Conhecer os princípios estruturantes da ordem natural e humana seria, então, a forma de desvendar seus segredos. Em síntese, na modernidade a razão proclama-se o único recurso seguro de conhecer o mundo e orientar o comportamento humano. 
Esse breve passeio histórico mostra-nos que os cenários de pluralidade, mencionados acima, estiveram constantemente permeados pela leitura universalista e homogênea das relações humanas. Tal percepção de ordem homogênea, ao mesmo tempo divina, natural e humana, persiste até hoje no imaginário de muitos. É exatamente essa ideia de não contradição, de homogeneidade e universalidade, hegemônica desde os primórdios de nossa cultura, o pomo de discórdia entre modernos, ainda modernos e pós-modernos.

Mais uma vez, importa destacar o risco de uma interpretação linear dessas mudanças. Na verdade, as críticas ao racionalismo moderno, muito antes de aflorarem no debate sobre modernidade/pós-modernidade, tal como foram formuladas por Lyotard (2008) e Harvey (1993), já faziam parte das reflexões de Nietzsche (1844-1900) e Heidegger (1889-1976). A história evidencia que, na segunda metade do século passado, paralelamente ao padrão epistêmico das ciências naturais, discutia-se a ideia de uma ordem artificial de origem humana, marcada pelas paixões e aspirações difusas, mutantes, imprevisíveis e distantes de qualquer ordem ideal, teológica ou deontológica.

Recuando ainda mais na história, constatamos que os prenúncios desse movimento já podem ser detectados na Idade Média cristã, porquanto a ideia de salvação se embasa não no destino, mas no livre arbítrio e na consequente ação do ser humano. Tais sementes ganharam vida na modernidade quando o indivíduo e a subjetividade foram alçados ao centro do universo humano. Não só Descartes ancorou na subjetividade o fundamento último da verdade, mas todo o projeto da episteme moderna centra no homem todas as possibilidades de salvação. O grande ideal iluminista, formulado de maneira incisiva por Kant, é o sujeito autônomo no manejo de sua razão, em vista de sua maioridade.

$\mathrm{Na}$ esteira do mesmo pensamento kantiano, em estreita relação com o empirismo inglês, reverteu-se a autopoiesis subjetivista cartesiana, na medida em que se postula a experiência como origem do conhecimento. Tal viragem foi traduzida, posteriormente, por Auguste Comte (1798-1857) e Karl Marx (1798-1857) nos seus estudos sociológicos que reforçavam a compreensão do homem como um ser dependente da trama envolvente de relações sociais nas quais está inserido. Lançava-se, assim, a raiz de um movimento histórico que estabelece íntima relação formativa entre 0 ser humano e o contexto. No entanto, o homem sempre se considerou o condutor da história e, especialmente desde a modernidade, o condutor de sua própria trajetória.

Hoje muitos entendem que chegamos ao ponto crítico de inversão dessa relação. Conforme enfatizam Adorno e Horkheimer, é "pela mediação da sociedade total, que engloba todas as relações e emoções, (que) os homens se reconvertem exatamente naquilo contra o que se voltara a lei evolutiva da sociedade, o princípio 
do eu: meros seres genéricos, iguais uns aos outros pelo isolamento na coletividade governada pela força" (1985, p. 47). Na sociedade global e plural interconectada pelos meios de comunicação e pela mobilidade social, o risco de o ser humano se transformar num ser genérico chama cada vez mais a atenção de sociólogos, psicólogos, antropólogos e pedagogos. Devido à crescente influência e confluência de diferentes culturas, visões de mundo e concepções éticas, torna-se vital encontrar caminhos para o processo formativo em termos de políticas públicas, de conteúdos e procedimentos pedagógicos. Essa é a grande questão que gera preocupação, incerteza e mesmo desânimo na maioria daqueles que trabalham com educação, fora ou dentro da escola.

À busca de alguma luz, podemos iniciar perguntando pela razão de tantas incertezas e polêmicas quando se trata da formação do ser humano no cenário contemporâneo. Abre-se imediatamente um imenso leque de questões que poderiam e deveriam ser mencionadas. De forma breve e panorâmica, podemos resumir o cenário nos seguintes termos: antigamente, como vimos acima, existia uma pluralidade de sociedades e culturas, cujos contatos eram restritos a limites temporais e geográficos. A confluência e a imbricação cultural, resultado dos recentes mecanismos de mobilidade e comunicação, representam um cenário ao mesmo tempo essencialmente novo e de alta pregnância em termos de formação das pessoas. A lembrança de alguns apontamentos históricos permite-nos, de um lado, evitar a interpretação linear da pluralidade como um fenômeno sem precedentes históricos e, de outro, reconhecer a sociedade plural como um evento novo, sem similar na história.

A cultura assume características variadas, divergentes e contraditórias, tornando-se arredia à estratégia cognitiva de enquadrá-la em sentidos únicos, excludentes e redutores. Ainda estamos acostumados à forma cartesiana de pensar, cujo ideal epistêmico funda-se sobre verdades simples, binárias e maniqueístas. A própria ciência natural, que desde seu início se movimentou sobre esses trilhos, fez no princípio do séc. XIX descobertas revolucionárias. A mecânica de Newton (1687), caracterizada pela observação linear e harmônica do movimento dos corpos expresso em termos matemáticos precisos, exatos e uniformes, foi amplamente vitoriosa até o momento em que se viu confrontada com a física quântica de Max Planck (1900) e a teoria da relatividade de Albert Einstein (1905). A primeira estava focada no estudo de objetos microscópicos da estrutura atômica, enquanto a segunda ocupava-se da gravitação universal e do eletromagnetismo de objetos com grande velocidade e/ou massa. Tanto a mecânica quântica, quanto a teoria da relatividade constataram que seus objetos de observação, sendo de natureza variável - ora onda, ora partícula - e suscetíveis à interferência do observador, eram essencialmente inexplicáveis pelos métodos da física clássica newtoniana. 
Colhidas do coração do objetivismo, essas referências representam certo débacle do cientificismo moderno e um alívio para as ciências humanas e sociais, tradicionalmente vistas com um algum desdém pela falta de objetividade. Tanto as ciências físicas quanto as humanas e sociais parecem, desde então, fadadas a aceitar um paradigma epistêmico aberto à incerteza. Sociólogos importantes como Auguste Comte (1798-1857), Emile Durkheim (1858-1917) e Karl Mannheim (1893-1947), inspirados nos princípios da física tradicional, tentaram elevar a sociologia ao mesmo patamar de cientificidade da física clássica, ou seja, ao plano da objetividade, da universalidade e da cientificidade. Foi um projeto frustrado que encontrou consolo nos avanços da física pós-clássica. $\mathrm{O}$ que prevaleceu nos dois campos foi a tendência de reconhecer o circunstancial, o relacional, o mutante e a incontornável interferência do observador, isto é, a existência de uma ordem artificial de base racional distinta do plano ordenado por leis externas ao humano, naturais ou divinas.

Para o campo das ciências humanas, Bauman salienta a ambiguidade das condições históricas, ao produzirem ambivalências de sentidos de mundo e cultura na tensão entre "livre criatividade" e "regulação normativa". São dois elementos distintos da "ideia compósita de 'cultura', que significa tanto inventar quanto preservar; descontinuidade e prosseguimento; novidade e tradição; rotina e quebra de padrões; seguir normas e transcendê-las; o ímpar e o regular; a mudança e a monotonia da reprodução; o inesperado e o previsível” (2012, p. 18). As pessoas, imersas em determinados universos simbólicos e culturais, de um lado, necessitam partilhar símbolos, conceitos, valores, ideais, imagens de mundo como elementos norteadores de sua formação; de outro, precisam rejeitar para preservar sua autonomia e liberdade. A formação significa o tenso movimento entre ouvir e ser ouvido, reconhecer e ser reconhecido, rejeitar e ser rejeitado, influenciar e ser influenciado, reconhecer e ser reconhecido.

No movimento persistente entre os polos desses binômios, realiza-se a formação humana, em ambientes tanto formais quanto informais de educação. $\mathrm{O}$ aporte novo, próprio das sociedades complexas e plurais, é o caráter instável e plural desse universo formativo. Perde-se a permanência e a fixidez que conferiam autoridade e legitimidade aos processos formativos tradicionais em que objetivos claros e socialmente referenciados justificavam os procedimentos impositivos usados para "transmitir" conhecimentos e posturas éticas vinculantes a serem incorporados com resignação e conformismo. Ordem, disciplina, respeito, obediência e humildade eram pressupostos naturais de qualquer relação formativa.

Com a crise das certezas epistêmicas e éticas e a instauração de um mundo plural, complexo e instável, estremecem esses pressupostos da educação tradicio- 
nal. Uma das principais diferenças entre a formação tradicional e a contemporânea é a reestruturação do processo formativo, agora baseado em nova constelação cultural destituída das características de estabilidade e permanência e, portanto, mutante, instável e líquida, segundo a conhecida metáfora de Bauman (2001). Essa mudança redefine profundamente a relação ensino-aprendizagem, substituindo a verticalidade monológica pela horizontalidade dialógica. Diálogo e busca, comunicação e construção tornam-se as novas referências da interpretação/leitura do real e dos processos dinâmicos de constituição de identidade. Objetividade e subjetividade, ego e alter, permanência e transição passam a ser os polos seminais de uma nova dinâmica formativa, relacional e fluida, ladeando o relativismo à busca de novas permanências dialógicas, sempre provisórias, ancoradas apenas no tempo transitivo da cultura construída pelo homem.

À medida que se abre mão da eterna busca humana por certeza e estabilidade ancoradas na transcendência, instaura-se uma crise civilizatória de proporções nunca vistas, uma vez que está em jogo o próprio modelo de racionalidade adotado pela humanidade até o presente. $\mathrm{O}$ que parece ter sido a eterna aspiração do humano - o conhecimento seguro, permanente e universal como fonte de orientação do agir humano - esfuma-se no ar, cedendo lugar à sempre renovada indagação. Como respostas, o homem não pode esperar mais que permanências provisórias de acordos parcelares e temporais, encadeados ao fluxo da história. O rumo é conduzido apenas pela incontornável necessidade de encontrar respostas para as perguntas essenciais a respeito do sentido da vida, do mundo, da sociedade. A permanência em meio ao infindável movimento dialógico talvez seja a sempre renovada busca de referências de conduta, configuradas e reconfiguradas na dinâmica vital e cultural da história.

Do ponto de vista metodológico, são essenciais a compreensão e a interpretação ou, numa palavra, a hermenêutica do real, que entende o conhecimento como processo aberto em permanente tensão e constituição. $\mathrm{O}$ ser mutante coloca-se como desafio ao dever ser. $\mathrm{O}$ dever ser, espinha dorsal do formativo, tradicionalmente articulado em torno da perspectiva do permanente e universal, perde sua ancoragem e seu ponto de sustentação legitimante, devendo emergir agora da dinâmica indagativa, dialógico-criativa. A única postura capaz de dar conta dessa relação é o diálogo como dimensão central do processo formativo. Na formulação de Habermas, "a identidade da regra na pluralidade de suas realizações não descansa em invariações observáveis, mas sim na intersubjetividade de sua validade” (1999, p. 31).

$\mathrm{E}$ é sobre esse ponto da intersubjetividade que incidem os movimentos, as diferenças e os conflitos da sociedade plural, provocando uma viragem na ideia de individualismo fixada na modernidade. Verena Stocke lembra que "o individualismo é o valor cardinal das sociedades modernas. O surgimento do individualismo 
significará simultaneamente a cegueira ante o social. A ideologia moderna é individualista na medida em que valoriza o indivíduo concebido como sujeito moral, independente e autônomo e ignora ou subordina a totalidade social" (2011, p. 13). É esse individualismo paradigmático que está sendo relativizado pela nova postura intersubjetiva do agir comunicativo (HABERMAS, 1999).

A cultura pode ser definida como um processo de intercâmbio entre indivíduos, grupos e sociedades no seu empenho pela vida e sobrevivência. Então, a própria cultura passa a ser entendida como um processo em movimento. $\mathrm{O}$ indivíduo, na dinâmica de aculturação, não se insere num contexto cultural homogêneo e fixo, como ocorria no passado; ele se acultura numa sociedade envolta em tríplice movimento: a sociedade plural, a sociedade global e a sociedade em devir. Esse devir, em si desconcertado, a permanência, sempre frágil e provisória, mas essencial à vida humana, inscreve-se no âmbito da criatividade crítica do agir comunicativo. Nesses termos, a permanência emerge no e do devir por obra do argumento humano ancorado nos princípios de justiça social, democracia e respeito à pluralidade. Sobre o pano de fundo desses direitos, a busca do entendimento dialógico desinstala 0 universalismo essencialista colonizador do processo formativo, assumindo o plural como "essência" e o entendimento como estratégia da vida humana.

Essas características refletem a fragilidade, a provisoriedade, enfim, a historicidade de cada cultura resultante das estratégias de sobrevivência material e espiritual em contextos históricos, materiais e geográficos diferenciados. Vista isoladamente, cada cultura representa um sistema de tradições e relações sociais harmonizado, assumido e incorporado por seus integrantes, cuja preservação é essencial à vida presente e futura do grupo. As grandes dificuldades surgem quando as fronteiras entre as culturas tornam-se permeáveis, dando início tanto às tentativas de aproximação e entendimento quanto ao confronto e à luta por hegemonia e poder.

Sociedade plural não é outra coisa se não esse panorama da humanidade multicultural, ou seja, o cenário em que as incongruências entram em contato e confronto na luta por espaços, poder e domínio. O grande desafio que se coloca, então, é a harmonização entre, de um lado, o direito à identidade cultural com tudo o que isso importa e, de outro, a necessidade da convivência, do respeito e do reconhecimento das identidades culturais entre si. Esse é o desafio da contemporaneidade que ora se despede da colonização essencialista para ingressar numa nova cultura da convivência de culturas com base no entendimento e reconhecimento.

Embora não haja espaço aqui para uma análise mais aprofundada, não podemos deixar de mencionar a imbricação cultural hoje em curso, na medida em que as culturas passam a ocupar espaços comuns em razão da mobilidade física ou virtual. 
Crises econômicas, conflitos armados ou religiosos, busca de melhores condições de vida provocam enormes movimentos migratórios que resultam na confluência de culturas, gerando conflitos, ambivalências e paradoxos culturais, os quais, antes mais restritos às relações interculturais, ganham agora relevância intracultural. Esse é o cenário de muitos países europeus, onde, no interior das mesmas fronteiras, convivem pessoas que, tendo a mesma nacionalidade, deveriam, em princípio, partilhar da mesma cultura, mas que, de fato, pertencem a culturas diferentes. Nesses contextos, política, moral, religião e, portanto, também formação humana constituem um cenário de vozes múltiplas, de diferentes identidades e distintos vetores formativos. Embora na Europa tal realidade seja mais flagrante por razões históricas e econômicas, em maior ou menor medida, essa condição dissemina-se pelo mundo.

No contexto dessa realidade, na qual o ignorar-se já não é possível, abrem-se duas possibilidades de sentidos opostos: o confronto ou o encontro. O confronto é o caminho da hostilidade, da intolerância, da agressividade e da barbárie; o encontro, ao contrário, é a busca do entendimento, do respeito e do reconhecimento. São as duas faces do cenário das relações humanas, políticas e culturais do mundo de hoje. Grande parte dos conflitos, das guerras, das violências, do subdesenvolvimento, da fome e da miséria está relacionada às escolhas diante dessas possibilidades. Por isso, podemos dizer que essa encruzilhada de encontro e conflito cultural é preocupação fundamental da política, da antropologia, da sociologia e da educação. No campo da filosofia, são paradigmáticas as leituras de Jürgen Habermas (1981), Apel (1990), Rawls (1971), MacIntyre (2006), Honneth (2003), Sen (2009) e tantos outros. São autores que se dedicam ao estudo das possibilidades de entendimento, convivência, respeito e reconhecimento.

No dizer de Bauman, "a filosofia, que tende, por natureza, a pensar a Eindeutigkeit (não ambiguidade), lógica, coerência e clareza num mundo que não tem qualquer dessas características" [...] sente essas "contradições como paradoxos: espinhos dolorosos na carne da filosofia - esse projeto hercúleo de reconstruir o mundo confuso da experiência humana segundo o padrão de elegância e harmonia encontrado apenas na serena regularidade do pensamento" (2012, p. 21-2). E é esse um dos mais urgentes temas da filosofia hoje: aprender a pensar um mundo resistente à harmonia e à regularidade. Ao mesmo tempo, trata-se de um dos desafios mais centrais da praxis educativa: formar um ser humano íntegro num mundo desintegrado; formar um sujeito nucleado num contexto sem núcleo; formar um sujeito articulado numa realidade desarticulada; formar um sujeito harmônico numa realidade dissonante; formar um sujeito ético numa realidade sem valores; formar um sujeito sensível numa sociedade violenta; formar um sujeito democrático numa sociedade excludente; formar um sujeito pacífico num mundo em guerra. 
Como mencionado acima, a tendência parece ser o abandono do transcendentalismo metafísico, dos sentidos e valores únicos e universais, em favor de novas pautas de entendimento que incluem a diferença e a desarmonia. O que à primeira vista pode parecer simples é, na verdade, um dos mais complexos, difíceis e urgentes desafios da contemporaneidade. Projetar um mundo à maneira de um mosaico harmônico de peças culturais de formatos e colorações distintas é, certamente, simples demais. Os tecidos históricos e vivos das diferentes culturas, com suas tradições, seus valores, suas visões de mundo e de interesses políticos, econômicos e geográficos muito diversos implicam, necessariamente, tensão e adversidade. Como pensar, então, o formativo nessa paradoxal situação de "uma sociedade que sabe, deve saber, que não tem significação garantida, que vive sobre o caos, que ela própria é o caos que precisa dar a si mesmo uma forma, forma esta que não pode ser estabelecida de uma vez por todas"? (BAUMAN, 2012, p. 28).

A ambivalência dos símbolos culturais, flutuantes entre fronteiras esponjosas, representa enorme desafio, em termos tanto teóricos quanto práticos. Num contexto em que as fronteiras nacionais, culturais, étnicas, éticas e mesmo religiosas desfazem-se no ar, para lembrar a famosa expressão de Marx, confundindo-se num oceano turvo e imperscrutável de relativismos e ambivalências de toda a sorte, que norte dar aos processos formativos? Esse é o grande desafio posto aos educadores do nosso tempo. Mesmo sabendo que ainda não temos uma resposta e pressentindo que certamente jamais a teremos em definitivo, o encontro e o entendimento na diferença são tarefa incontornável da formação individual e social do futuro. Estamos no início de uma caminhada cheia de percalços da qual uns têm mais, outros menos consciência.

O importante é entender que os fenômenos culturais são socialmente produzidos, e não resultado da tradução de princípios transcendentais. Inclusive, estes últimos devem ser considerados como resultantes das relações dos homens entre si e o meio. Na esteira do "fim da história" de Francis Fukuyama (1992) e do "fim da geografia” de Paul Virílio (1993), podemos perguntar se, diante das transgressões, dos rompimentos de fronteiras e do estabelecimento de hegemonias econômicas, estéticas e linguísticas, não seria legítimo falar, também, do fim das culturas. Certamente essa hipótese de uma nova paisagem homogênea seria apressada, tendo em vista as reações e resistências das culturas cuja bandeira é a luta pela preservação de suas identidades. A homogeneização cultural da qual tanto se fala, na verdade, é predominantemente de natureza econômica. Ulrich Beck concede que "está surgindo um só mundo, mas não como reconhecimento da multiplicidade e da abertura recíproca, vale dizer de uma imagem pluralista e cosmopolita do si mesmo e do outro, senão que, bem ao contrário, como um só mundo mercantil. 
Neste mundo as culturas e as identidades locais se desenraizam e substituem por símbolos mercantis, procedentes do desenho publicitário e dos ícones das empresas multinacionais" (2008b, p. 72). Não obstante, no real cenário de transgressão e do rompimento de fronteiras que colocam em cena o conceito de porosidade como marca do nosso tempo histórico, o debate sobre a homogeneização cultural de qualquer modo está posto. $\mathrm{E}$ é precisamente a área de educação uma das mais sensíveis a essa inovação.

Dois fatores que, de um lado, encontram-se na origem e interferem no processo de monoculturalização e, de outro, afetam de modo especial a educação, são os de mobilidade e comunicação. Não há aqui espaço para aprofundar essas questões, mas cabe, ao menos, assinalar sua importância num mundo cada vez mais encantado com as infinitas vantagens e assustado com o potencial invasivo da informática. Binômios como "fora/dentro", "perto/longe", "igual/diferente", "eu/outro" passam por um processo de simbiose de fronteiras, mesclando, inclusive, as tintas de conceitos antes tão definidos e separados, como "certo/errado", "verdadeiro/falso", "belo/feio". Como vemos, encontram-se em movimento dimensões seminais do humano, do conhecimento, da ética e da sensibilidade absolutamente centrais ao processo de formação humana.

É difícil avaliar o que essa fluidez ou, na expressão de Bauman (2001), essa liquidez representa em termos de formação humana. Quando a dicotomia entre o bem e o mal se desfaz e quando se admite o que Edgar Morin (2000) chama de complexidade, as decisões passam a depender da avaliação dos sujeitos nas circunstâncias concretas. E isso é, mais uma vez, paradoxal, pois, quanto mais se insere na realidade múltipla e contraditória, mais o sujeito carece de capacidade reflexiva de avaliação e julgamento. Ulrich Beck nos ensina que, "mediante a tendência secular e a individualização, se diz logo, se torna poroso o conglomerado social, a sociedade perde consciência coletiva e, por conseguinte, sua capacidade de negociação política. A busca de respostas políticas às grandes questões do futuro já ficou sem sujeito e sem lugar" (2008b, p. 25). Tal dificuldade transforma, na base, a tradicional prática de transmitir aos educandos um receituário de posturas éticas ou epistêmicas verdadeiras ou falsas, boas ou más. Trata-se muito mais de educar as pessoas para que tenham condições de decidir, em situações concretas, como melhor agir. Em outras palavras, trata-se de educar os sujeitos não para se adaptarem passivamente a normas preestabelecidas, mas para assumirem a responsabilidade da decisão correta, vale dizer, para a responsabilidade do pensar.

Essa é uma revolução epistêmica, ética e estética que desestabiliza a base de sustentação do processo tradicional de formação que necessita ser repensado em profundidade. Os conceitos de ensinar e de aprender, as novas constelações teórico- 
-metodológicas, as posturas éticas e as formas de sensibilidade, bem como o incremento e a obsolescência dos conteúdos representam novos desafios para as teorias e práticas pedagógicas. Mudam não somente os conteúdos, mas também a nossa relação com eles; mudam os valores e a nossa postura frente às normas; mudam a sensibilidade e a expressão de nosso gosto. Tudo isso, por sua vez, interfere na relação pedagógica entre pais e filhos, entre professores e alunos. Conceitos como ensino e aprendizagem assumem ares de relativismo e fluidez. A comunicação rápida e fugaz, focada na informação e não no conhecimento, engendra verdadeira inundação e sufocamento de futilidades, cuja procedência e veracidade não são aferíveis. Com isso, muitos dos conceitos angulares da educação coloram-se com tintas de superficialidade, pela celeridade e vida breve, pela falta de coerência, sequencialidade e memória.

O rompimento das fronteiras de espaço e tempo do grupo, da comunidade e do Estado, que, de certo modo, favoreciam a proximidade física e cultural, provoca inevitável regressão da presencialidade, regressão esta que se faz sentir na família, na escola e na comunidade, reduzindo nesses espaços a relevância da autoridade formativa em termos morais, epistêmicos e estéticos. Os novos recursos eletrônicos (internet), ágeis e descomprometidos, assumem, gradativamente, o vazio aberto pela incapacidade das instituições tradicionais de responder aos novos desafios. As recentes manifestações políticas, convocadas por meio de redes sociais, são exemplo claro dessa tendência. Ainda que os manifestantes vivessem em família, frequentassem escolas ou participassem da comunidade, nem a família, a escola ou a comunidade saberiam e muito menos entenderiam o que estava acontecendo. Tais instituições, tradicionalmente tão centrais à socialidade, ficaram surpreendente e assustadoramente marginalizadas do importante momento de transformação política e social. Foram manifestações sem cor, classe, religião, ordem, autoridade ou objetivos definidos. Mesmo assim, deixaram uma grande mensagem: estamos cansados do descolamento entre sociedade e política. Enquanto as práticas sociais estavam estreitamente ligadas ao grupo, à comunidade, à família e, também, à escola, a atuação dessas instituições, evidentemente, refletia-se diretamente sobre o panorama da formação. No vácuo deixado pelo descompasso e pela obsolescência dessas instituições, as grandes redes representam uma nova forma de dizer nós, o "nós" da inclusão, da aceitação, do reconhecimento. Talvez seja essa uma forma atabalhoada, mas impactante de dizer que as relações formativas precisam ser repensadas.

A expansão da territorialidade pelo rompimento das fronteiras geográficas, culturais, étnicas e grupais pelos novos mecanismos de comunicação, com a veiculação de novos valores e ideais poluídos de individualismo, pragmatismo, ego- 
ísmo, utilitarismo e mercadorismo, interfere diretamente na ordem do formativo. As dimensões epistêmica, ética e estética, nucleares ao processo formativo, são formuladas a partir dos interesses sistêmicos da ordem econômica globalizada. Na leitura de Beck, "a globalização significa a perceptível perda de fronteiras do agir quotidiano nas distintas dimensões da economia, da informação, da ecologia, da técnica, dos conflitos culturais e da sociedade civil..." (2008b, p. 42). O sistema impõe-se de forma violenta sobre a vida quotidiana, forçando a todos a adaptarem-se e a responderem. O dinheiro, a tecnologia e a informação invadem e intoxicam o espaço da subjetividade no qual deveria ocorrer o processo formativo. Efeito extremo gera tal "fatalidade" contemporânea quando os indivíduos incorporam o responder e o adaptar-se como o sentido máximo de sua perfectibilidade formativa.

$\mathrm{O}$ economicismo faz tabula rasa das diferenças e das identidades culturais, agregando tudo em torno da produção, do mercado, do lucro e do consumo. A economia passa a ser a porta de entrada de uma cidadania restrita à capacidade de produzir, comprar e consumir. Esses são os vetores da cultura economicamente globalizada limitante, restringente e empobrecida. $\mathrm{O}$ estreitamento economicista refletido na própria linguagem, postado na contramão do paradigma habermasiano do agir comunicativo, inviabiliza a tradução conceitual da alteridade cultural e, assim, as possibilidades de entendimento e reconhecimento. $\mathrm{O}$ resultado são os julgamentos superficiais e descontextualizados, banhados na soberba, no menosprezo e na oclusão frente ao outro.

As fontes comuns de informação, tais como jornais, revistas, televisão e internet, estão repletas de informações tópicas e dispersas, muito distantes do verdadeiro conhecimento. Essa é a nova expressão da indústria cultural, à qual se referem Adorno e Horkheimer. As informações são como estrelas cadentes, cuja luz risca por instantes o firmamento do conhecer, oferecendo-nos um belo espetáculo, porém ligeiro e fugaz, superficial e pobre demais para revelar algo sobre os mistérios dos universos culturais, por natureza difíceis e resistentes ao entendimento. As culturas e as pluralidades de modo geral são como universos herméticos que, na atualidade, aproximam-se, entrecruzam-se e confrontam-se, mas ainda não se entendem. O único caminho para alcançar a abertura, o conhecimento mútuo, o entendimento e, assim, o reconhecimento é a tradução dos conceitos, das imagens, das visões de mundo, dos valores, das tradições e dos ideais.

Parece que estou falando ao modo dos antropólogos, ocupados com culturas primitivas e remotas, cujos símbolos pararam no tempo, sendo, por isso, impenetráveis ao olhar não especializado. No entanto, sem viajar por tempos e espaços distantes, é bastante olhar em volta para constatar quão pouco entendemos do outro, até mesmo daquele que partilha conosco tempo e espaço. Nós brasileiros, 
que vivemos num país continental de diferenças culturais acentuadas, sequer precisamos ir além-fronteiras para nos darmos conta da nossa ignorância mútua. Ora, se quisermos construir uma nação e acreditarmos que, para isso, faz-se necessário explorar a dimensão social e política do formativo, precisamos antes de tudo conhecer e reconhecer o outro brasileiro. Não é possível a formação cidadã sem conhecer e respeitar as especificidades culturais constituintes do horizonte no qual ganham sentido as necessidades e expectativas a serem traduzidas nas práticas formativas. Os diferentes espaços urbanos e rurais, as distintas classes sociais, as culturas regionais, as etnias, raças e religiões e até mesmo as gerações que dividem o mesmo tempo histórico no mundo acelerado de hoje ostentam entre si diferenças culturais cujo desconhecimento redunda, necessariamente, numa formação despótica e autoritária.

A escola é um lugar de socialização onde essas diferenças aparecem de forma mais significativa, exigindo posturas de entendimento e reconhecimento. Para compreendermos essas aproximações que se adensam sob o impulso dos mecanismos de mobilidade e de comunicação e alcançarmos uma efetiva compreensão do outro, há uma longa e difícil travessia de ida ao outro e de retorno a si mesmo num movimento de superação das barreiras conceituais, éticas e perceptivas. A tradução, mencionada anteriormente, pressupõe um exercício de desconstrução da própria arrogância e surdez e a reinvenção da esquecida virtude da escuta do outro, dos sentidos de sua palavra. Essa é uma condição essencial sem a qual não se chega ao reconhecimento do qual nos fala Axel Honneth (2003). Traduzir não se reduz ao exercício de trazer o mundo do outro para o nosso mundo, pela simples razão de que o meu universo conceitual não tem os recursos suficientes para abranger e abrigar os sentidos e significados do outro. Faz-se necessário recriar os mundos conceituais num novo espaço de entendimento dialógico.

Esse é o sentido mais profundo do encontro com o outro: o entendimento, a compreensão, o reconhecimento e a transformação de ambas as partes. Bauman expressa isso nos seguintes termos: "A tradução é um processo de autocriação e também de criação mútua; longe de exercer a autoridade, de colocar o traduzido no devido lugar, o tradutor deve primeiro elevar-se ao plano do traduzido; mas se a tradução cria o texto traduzido, também cria o tradutor [...]”. Por isso,

[...] a tradução é um diálogo contínuo, incompleto e inconclusivo que tende a continuar assim. $\mathrm{O}$ encontro de duas contingências, ele próprio, é uma contingência; nenhum esforço impedirá que assim o seja. $\mathrm{O}$ ato da tradução não é um evento singular que possa acabar com a necessidade de novos esforços de tradução. O local de encontro, a terra de fronteira das culturas, é o território em que os limites são constante e obsessivamente traçados só para serem violados e retraçados vezes sem conta - e não menos pelo fato de os dois parceiros emergirem modificados de cada sucessiva tentativa de tradução (2012, p. 74). 
É o movimento da co-habitação e do reconhecimento. O tradutor deve ter consciência de que ele não olha desde um ponto de vista supracultural ou supra-histórico. Ou melhor, ele não está livre da imersão e da contingência. Sua própria realidade, seus produtos culturais, mas, sobretudo, seu próprio sistema operacional linguístico representam um mundo constituído historicamente à semelhança de todos os outros.

O reconhecimento da contingência, da especificidade que os caracterizam é condição imprescindível para a leitura, o entendimento e a tradução de textos culturais e, por conseguinte, também condição incontornável da formação de novos contextos. Assim grafada, essa palavra permite-nos entender o reconhecimento como processo de encontro de textos (culturais) abertos ao enriquecimento mútuo, livre de qualquer impulso colonizador. Traduzir, nesse sentido, não é capturar e prender outras culturas em redis conceituais estranhos, mas a criação de novos mundos conceituais de entendimento.

No dizer de Bauman

compreender, não censurar; interpretar, não ordenar; abandonar o solilóquio em favor do diálogo - parece ser este o preceito para as novas ciências humanas, mais humildes; porém, pela mesma razão, mais poderosas, prometendo aos homens e mulheres desnorteados que vivem em nossa era algum discernimento e um pouco de orientação para enfrentar a massa de experiências cada vez mais descoordenadas e amiúde contraditórias - e, pela primeira vez, capazes de cumprir suas promessas (2012, p. 75).

Compreender e interpretar não significam, simplesmente, anular e integrar; nem respeitar e reconhecer significam indiferença e permanência. Esse é o pesadelo que ameaça o sonho do encontro plural. Já ouvimos os pedidos de socorro de culturas ameaçadas de extinção e morte. A internacionalização e a globalização de mercado e a ideologia do tecnicismo utilitarista, produtivista e consumista trazem consigo a ameaça da hegemonia dos mais poderosos, ricos e racionais. As culturas sem expectativa tendem a aparelhar-se e dissolver-se, corroídas em suas identidades pela acidez do economicismo neoliberal globalizado, seja por força de imposições externas, seja por induzidas volições internas.

A universalização de uma língua, no caso, o inglês, portadora de conceitos e visões de mundo, de posturas epistêmicas, éticas e estéticas torna iminente o risco de transformar o cenário cultural num campo raso no qual as diferenças culturais só sobrevivem como lápides na memória dos aderentes sistêmicos. Essa possibilidade acende muitas luzes de alerta, assinalando riscos frente aos quais a humanidade deve se precaver. O mais trágico desses riscos talvez seja a perda das raízes identitárias preservadas vivas na linguagem. Importante não esquecer que as identidades culturais, éticas, estéticas expressas nas diferentes linguagens 
são tradições milenares que podem ser niveladas pelos tremores desse verdadeiro maremoto do mundo líquido que mistura as águas culturais num modo único de existência e coexistência.

É por essa razão que se fortalece o movimento internacional de defesa da identidade cultural frente aos riscos da integração globalizada de corte economicista. A globalização econômica traduz-se na linguagem estreitada do monetarismo que vai ocupando pouco a pouco os espaços das culturas num processo velado de desidentificação niveladora. A saída para essa corrosão do caráter identitário não é o enclausuramento, o fundamentalismo, a negação do outro, mas o entendimento pelo diálogo aberto, a começar pela revisão de nossas próprias certezas. Pensar no contexto da sociedade plural é um caminho sem fim por entre fronteiras porosas, sempre penoso, difícil e inconcluso. Um caminho sem rota definida; um caminho que se faz ao caminhar, segundo a sabedoria do poeta.

O fio condutor dessa postura é a sempre renovada pergunta a respeito do que são e do que devam ser o homem, a sociedade e o mundo. Para isso, precisamos reinstituir a ágora como espaço de reconhecimento, dignidade, justiça e diálogo de todos com todos, iguais e diferentes. Diálogo significa reconhecer as razões dos outros, integrando-as na conversa, na busca do valor universal do humano, aberto às diferenças e circunstâncias humanas. A humanidade, muito mais que uma essência a ser consagrada, é uma construção do pensar conjunto e articulado no contexto de um mundo plural de racionalidades, éticas e estéticas. Todos os que se dispõem a participar do processo de pensar a vida possível na sociedade plural devem estar sempre e permanentemente dispostos a revisar suas certezas. Pensar, ouvir e argumentar talvez sejam as maiores virtudes do nosso tempo e a mais importante tarefa da formação. Dessas virtudes, nem as ciências com suas metodologias eficientistas, nem mesmo a educação com seus conteúdos e estratégias performáticas tem algo a dizer; pensar, escutar e argumentar ou, numa palavra, o diálogo criativo, crítico e arriscado deve representar o centro do processo formativo no contexto das sociedades plurais.

Precisamos saber como se produzem nossas verdades; precisamos saber quem somos, quem achamos que devemos ser, quem queremos ser; precisamos perguntar pelo que efetivamente importa como pessoas humanas e recusar a realidade produzida que nos impingem como importante; precisamos aprender a não confundir a ideologia e as práticas sistêmicas com a realidade; precisamos evitar que a racionalidade do sistema balize o processo formativo. Se não nos dermos conta disso, nossa docência e pesquisa se adaptarão a essa realidade e nós professores seremos produzidos por esse discurso. Sem perceber, nos tornaremos agentes do sistema, parte, portanto, do jogo. Nossas práticas aceitarão o enquadramento, assumirão o espírito de manada, como diz Adorno (1985). 
Formar-se na sociedade plural significa reconquistar a subjetividade; significa gerar em nós a recusa do que nos tornamos, seres produzidos; significa não aceitar o que o sistema quer que sejamos: cabeças bem feitas, adaptadas, monológicas, números e categorias; significa entender que a realidade existente não é tão pétrea quanto parece e que pode ser diferente; significa trocar a aderência pela resistência, o êxito pelo risco; significa ultrapassar os estreitos limites da incorporação de conhecimentos e habilidades exigidos pelo mercado e assumir o risco do pensamento autônomo. Mas formar-se na sociedade plural significa, sobretudo, dar-se conta da diferença, da alteridade, do outro como nova categoria fundante da epistemologia, da ética e da estética.

\section{Human formation and plural societies}

\section{Abstract}

This essay is about the human formation in plural societies, beginning from a brief historical recovery of the problem to, then, focus in the contemporary scenario from a wider epistemic perspective that aims demonstrate that the plurality/complexity problem is not restricted to the humanities field of work. It is about much more than a general crisis of the certainties of modern racionality. Finally, attempts to show that the plurality theme challenges the pedagogical authority whose practices were based precisely in the certainty and authority concepts, which must be rethought from the plurality, acknowledgment and dialogue perspectives.

Keywords: Formation. Plural societies. Alterity. Acknowledgment. Dialogue (Dialogicity).

\section{Referências}

ABBAGNANO, Nicholas; VISALBERGHI, Aldo. A história da pedagogia. México: Fondo de Cultura Económico, 1990.

ADORNO, Theodor; HORKHEMER, Max. Dialética do esclarecimento. Rio de Janeiro: Jorge Zahar Editor, 1985.

APEL, Karl-Otto. Diskurs und Verantwortung. Frankfurt: Suhrkamp, 1990.

BAUMAN, Zygmunt. Modernidade líquida. Rio de Janeiro: Jorge Zahar Editor, 2001. . Ensaios sobre o conceito de cultura. Rio de Janeiro: Jorge Zahar Editor, 2012.

BECK, Ulrich. La sociedad del riesgo mundial. Barcelona: Paidós, 2008a.

. Qué es la glogalización. Buenos Aires: Paidós, 2008b.

FOUCAULT, Michel. As palavras e as coisas: uma arqueologia das ciências humanas. São Paulo: Martins Fontes, 1981.

FUKUYAMA, Francis. O fim da História e o último homem. Rio de Janeiro: Rocco, 1992. 
GIROUX, Henri-Irénée. História da educação na antiguidade. São Paulo: EPU/MEC, 1975.

HABERMAS, Jürgen. Teoría de la acción comunicativa. Madrid: Taurus, 1999. v. II.

HARVEY, David. A condição pós-moderna. São Paulo: Loyola,1993.

HONNETH, Axel. Luta por reconhecimento. São Paulo: Editora 34, 2003.

LIPOVETSKY, Gilles. $O$ crepúsculo do dever: a ética indolor dos novos tempos democráticos. Lisboa: Publicações Dom Quixote, 1994.

LYOTARD, Jean-François. A condição pós-moderna. Rio de Janeiro: José Olympio, 2008.

MacINTYRE, Alasdair. Historia de la ética. Barcelona: Paidós, 2006.

MORIN, Edgar. A inteligência da complexidade. São Paulo: Petrópolis, 2000.

RAWLS, John. Uma teoria da justiça. Lisboa: Presença, 1971.

SEN, Amartya. The idea of justice. London: Pinguin Books, 2009.

STOCKLE, Verena. Gloria o maldición del individualismo moderno según Louis Dumont. Revista de Antropologia, v. 44, n. 2, p. 7-37, 2011.

VIRILIO, Paul. Espaço crítico. São Paulo: Editora 34, 1993. 